\title{
The Effect of Type-I Photoinitiators on the Kinetics of the UV-Induced Cotelomerization Process of Acrylate Monomers and Properties of Obtained Pressure-Sensitive Adhesives
}

\author{
Agnieszka Kowalczyk*(D), Mateusz Weisbrodt (D), Beata Schmidt (D) and Agata Kraśkiewicz \\ Department of Chemical Organic Technology and Polymeric Materials, Faculty of Chemical Technology and \\ Engineering, West Pomeranian University of Technology in Szczecin, 70-322 Szczecin, Poland; \\ mateusz.weisbrodt@zut.edu.pl (M.W.); bschmidt@zut.edu.pl (B.S.); kraskiewiczagata@gmail.com (A.K.) \\ * Correspondence: agnieszka.kowalczyk@zut.edu.pl
}

check for updates

Citation: Kowalczyk, A.; Weisbrodt, M.; Schmidt, B.; Kraśkiewicz, A. The Effect of Type-I Photoinitiators on the Kinetics of the UV-Induced

Cotelomerization Process of Acrylate Monomers and Properties of Obtained Pressure-Sensitive Adhesives. Materials 2021, 14, 4563. https://doi.org/10.3390/ma14164563

Academic Editor: Ricardo J. C. Carbas

Received: 2 July 2021

Accepted: 10 August 2021

Published: 13 August 2021

Publisher's Note: MDPI stays neutral with regard to jurisdictional claims in published maps and institutional affiliations.

Copyright: (c) 2021 by the authors. Licensee MDPI, Basel, Switzerland. This article is an open access article distributed under the terms and conditions of the Creative Commons Attribution (CC BY) license (https:/ / creativecommons.org/licenses/by/ $4.0 /)$.
Abstract: A new method of solvent-free acrylic pressure-sensitive adhesives (PSAs) based on UVinduced cotelomerization products was presented. The key acrylic monomers (i.e., n-butyl acrylate and acrylic acid) with copolymerizable photoinitiator 4-acrylooxybenzophenone in the presence of a selected chain transfer agent (tetrabromomethane, TBM) were used in the UV-cotelomerization process. Moreover, two kinds of UV-photoinitiators ( $\alpha$-hydroxyalkylphenones, HPs and acylphosphine oxides, APOs) were tested. Photo-DSC, viscosity, thermogravimetric, and GPC measurements for cotelomers were performed. The kinetics study revealed that the systems with APOs, especially Omnirad 819 and Omnirad TPO, were characterized by a much higher reaction rate and greater initiation efficiency than HPs systems were. Additionally, the APO-based syrups exhibited a higher solid content (ca. 60-96 wt\%), a higher dynamic viscosity (5-185 Pa.s), but slightly lower molecular weights $\left(\mathrm{M}_{n}\right.$ and $\left.\mathrm{M}_{\mathrm{w}}\right)$ compared to HP syrups. However, better self-adhesive features (i.e., adhesion and tack) were observed for PSAs based on cotelomers syrups obtained using APOs with lower solid contents (55-80 $\mathrm{wt} \%$ ). It was found that as the solids content (i.e., monomers conversion) increased the adhesion, the tack and glass transition temperature decreased and the type and amount of photoinitiator had no effect on polydispersity. Most of the obtained PSAs were characterized by excellent cohesion, both at $20^{\circ} \mathrm{C}$ and $70^{\circ} \mathrm{C}$.

Keywords: pressure-sensitive adhesives; radical photoinitiators; telomerization; bulk photopolymerization; acrylic syrups; adhesion

\section{Introduction}

Finding new techniques of materials joining (including the creation of thin-walled structures) is an important task for scientists and industry in order to ensure high functionality of the structure while respecting the principles of environmental protection [1]. This global trend also includes new, fast, and environmentally friendly methods of adhesives preparation, such as pressure-sensitive adhesives (PSAs). PSAs are a special class of adhesive materials used in many industrial assembly operations and most consumer applications [2,3]. PSAs do not harden but remain permanently sticky. They create a strong bond with the surface with only finger pressure and do not require activation by heat or water $[4,5]$. The most widely used are acrylic PSAs [6]. They are obtained predominantly by organic solvent radical polymerization or emulsion polymerization [7-9]. In both cases, the solvent (organic or water) must be removed in order to obtain a self-adhesive film. Increasingly, in the last decade, publications on ecological methods of PSAs preparation have been made, of which the most important are photopolymerization processes. Back et al. reported on a new pro-ecological method of obtaining solvent-free PSAs via visiblelight-driven photocatalytic radical polymerization [10] and photoredox-mediated radical polymerization [11]. Instead, Beak at al. showed the free radical bulk photopolymeriza- 
tion process as a method of obtaining acrylic syrups to prepared PSAs [12-17]. However, the resulting reaction products (prepolymers/syrups) had a high content of unreacted monomers, so the PSA film was UV-cured in the presence of volatile compounds and must be covered with a transparent release film to avoid oxygen inhibition. Moreover, the above-mentioned publications did not show the influence of various factors on the course of the bulk photopolymerization process.

Generally, the role of the photoinitiator (PI) in radical photopolymerization processes is crucial next to the source and dose of UV-radiation, exposure time, or the influence of oxygen. However, the effect of PIs on the course of the free radical bulk photopolymerization process has not been revealed so far. Gziut at al. revealed the influence of the type and amount of PIs on the free radical bulk photopolymerization processes of butyl acrylate, glycidyl methacrylate, and 2-hydroxyethyl acrylate. The received acrylate syrups were used to obtain structural adhesive tapes [18]. In principle, photoinitiators for radical polymerization are classified as cleavage (type I) and H-abstraction-type (type II) initiators [19]. Type I photoinitiators are mostly aromatic carbonyl compounds, e.g., benzoin and derivatives, benzile ketales, acetophenones, $\alpha$-hydroxyalkylphenones (HPs), and acylphospine oxides (APOs). The choice of a particular PI largely depends on the requirements of a specific application, taking into account the advantages and disadvantages of the selected PI. For example, APOs have been used in high pigmented formulations, where irradiation at longer wavelength is desired. The absorption of APOs $(350-380 \mathrm{~nm})$ match the emission spectrum of the main commercial light sources [20]. Furthermore, APOs are attractive to use because of their thermal stability and high reactivity of formed phosphonyl radicals. On the other hand, HPs have a strong absorption in the short-wave UV (230-270 nm) and weak absorption at longer wavelengths (up to $360 \mathrm{~nm}$ ) and can lead to deep curing using a medium-pressure lamp. Therefore, the HPs are very versatile and efficient photoinitiators [21]. A lot of work has recently been dedicated to a new system of free radical photopolymerization initiations. New type I and type II photoinitiators based on 2,2-dimethoxy-2-phenylacetophenone, benzophenone, and thioxanthone were proposed for the free radical polymerization of acrylates [22], carbazole derivatives for LED polymerization [23], carbazole phosphine oxides [24,25], and novel-water soluble polymeric photoinitiators for acrylate polymerization [26]. However, to the best of the authors' knowledge, there is no information in the literature about the most effective photoinitiators for the UV-initiated telomerization process.

This article is a continuation of the recent research presented on a new solvent-free method of PSA preparation for various applications [27], i.e., UV-induced cotelomerization process. Telomerization is a reaction of a polymerizable compound $(\mathrm{M})$ in the presence of a chain transfer agent $(\mathrm{YZ})$, which is provided to macromolecules $\mathrm{Y}(\mathrm{M})_{\mathrm{n}} \mathrm{Z}$, where $n$ is less than 100 but is not 1 [28]. Previously, we proved that the UV-induced cotelomerization process is an environmentally friendly and fast method of obtaining pressure-sensitive adhesives (PSAs) and the effect of a functional monomer (i.e., acrylic acid) was checked. Based on these studies, the optimal composition of the monomer mixture ( $n$-butyl acrylate, acrylic acid, and 4-acrylooxybenzophenone) for UV-cotelomerization was selected. Our previous and unpublished research showed that the key parameter influencing the self-adhesive properties of acrylic PSAs based on cotelomerization products (acrylic syrups, i.e., mixture of linear cotelomers and unreacted monomers) is the solid content (SC), which corresponds to the monomer's conversion. One of the factors affecting the SC values is the type and amount of PI used for initiation of the UV-cotelomerization process. This study presented the influence of commercially available type I photoinitiators ( $\alpha$-hydroxyketones- HPs and acylphospine oxides-APOs) on the course of the UV-cotelomerization process, properties of reaction products (cotelomer syrups), and selected self-adhesive features of solvent-free PSAs. The new method of receiving solvent-free PSAs presented here is noteworthy as it allows one to obtain adhesive binders with a low content of unreacted monomers in a short time (30 min or even less), which was incorporated into the polyacrylate structure during the UV crosslinking stage (in the presence of crosslinking monomer and without special 
screens to protect against the negative effects of oxygen). The resulting PSAs can be used for the production of masking tapes, self-adhesive labels, or other self-adhesive materials.

\section{Materials and Methods}

\subsection{Materials}

The following components were used for the preparation of BA/AA/ABP cotelomers: n-butyl acrylate (BA), acrylic acid (AA) (BASF, Ludwigshafen, Germany) as monomers; 4-acryloylooxybenzophenone (ABP, Chemitec, Scandiccy, Italy) as copolymerizable photoinitiator; tetrabromomethane (TBM; Merck, Warsaw, Poland) as telogen; and different type I radical photoinitiators:

(1) $\alpha$-Hydroxyalkylphenones (HPs): 2-hydroxy-1-(4-(4-(2-hydroxy-2-methylpropionyl)benzyl)phenyl)-2-methylpropan-1-one (Omnirad 127; IGM Resin, Waalwijk, The Netherlands) and 1-hydroxycyclohexylphenyl ketone (Omnirad 184, IGM Resins, Waalwijk, The Netherlands);

(2) Acylphosphine oxides (APOs): bis(2,4,6-trimethylbenzoyl)-phenylphosphineoxide (Omnirad 819; IGM Resins, Waalwijk, The Netherlands); 2,4,6-trimethylbenzoyldiphenyl phosphine oxide (Omnirad TPO; IGM Resins, Waalwijk, The Netherlands) and 2,4,6-trimethylbenzoyldi-phenylphosphinate (Omnirad TPOL; IGM Resins, Waalwijk, The Netherlands);

(3) Mixture of acylphosphine oxides (APOs blend): ethyl phenyl(2,4,6- trimethylbenzoyl)phosphinate (ca. $95 \mathrm{wt} \%$ ) and phenyl bis(2,4,6-trimethylbenzoyl)-phosphine oxide (ca. 5 wt\%) (Omnirad 2100; IGM Resins, Waalwijk, The Netherlands).

The structures of photoinitiators are shown in Table 1.The components were applied without purification. A hydroxyl-terminated polybutadiene resin Hypro 1200X90 HTB (CVC Thermoset Specialties, Emerald Kalama Chemical, Kalama, WA, USA) as a multifunctional monomer of the UV-crosslinking process was used, as previously reported [27].

Table 1. Structures of tested photoinitiators.

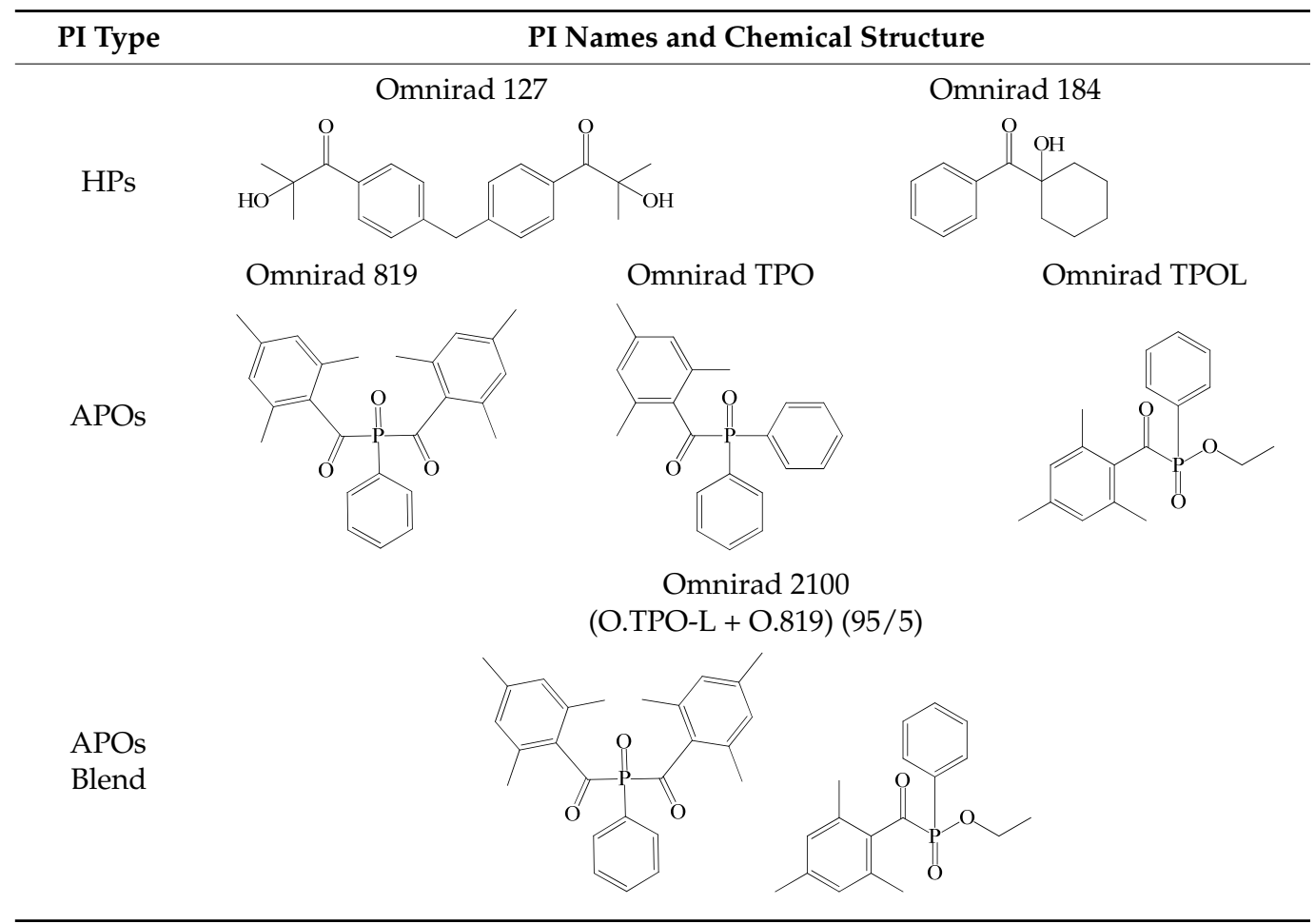




\subsection{Synthesis and Characterization of $B A / A A / A B P$ Cotelomers}

The cotelomerization processes of $\mathrm{BA}, \mathrm{AA}$, and $\mathrm{ABP}$ were initiated using different radical photoinitiators $(15,30$, or $45 \mathrm{mmol}$ per $50 \mathrm{~g}$ of monomers mixture) and tetrabromomethane ( $2.5 \mathrm{phr})$ as telogen was used. The reaction mechanism is presented in Figure 1. Mixtures of monomers and sample symbols are shown in Table 2.

\section{Initiation:}

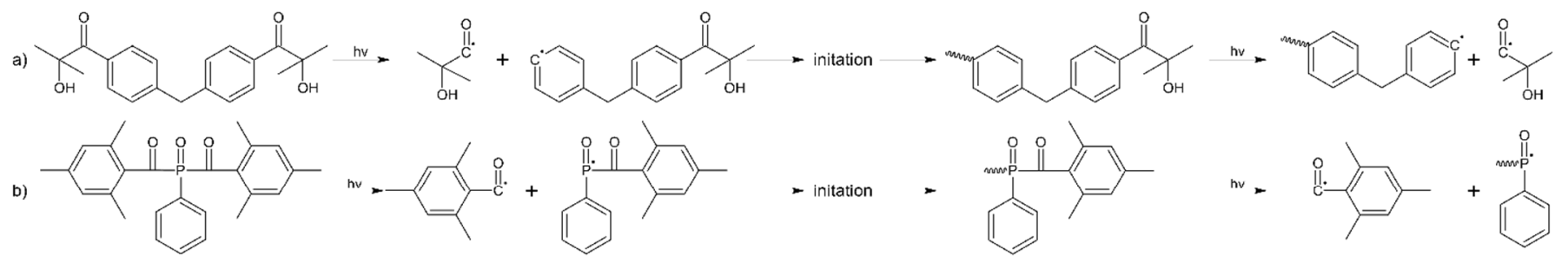

c)<smiles>O=C[C+]1CCCCC1O</smiles>

d)
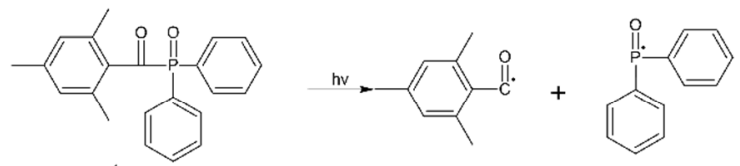

e)
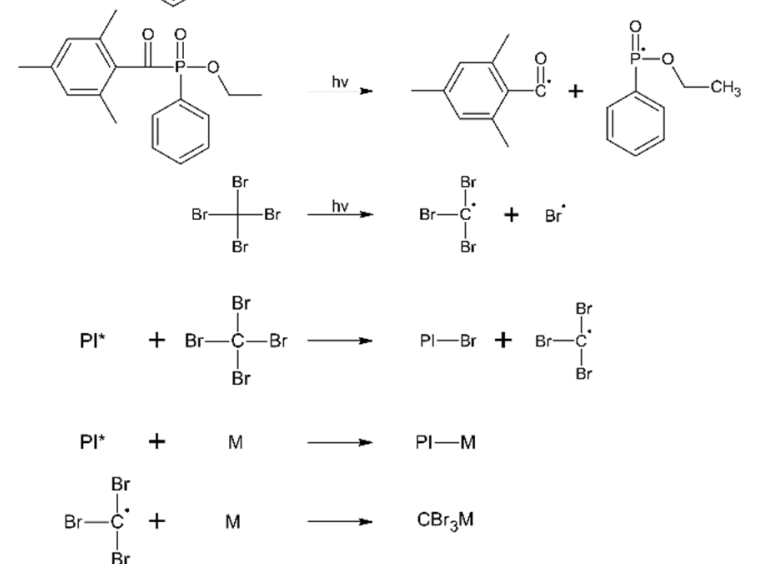

Propagation:

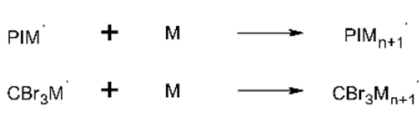

Chain Transfer:

$\mathrm{PIM}_{\mathrm{n}+1}+\mathrm{Br}-\mathrm{CBr}_{3} \longrightarrow \mathrm{R}^{1} \mathrm{M}_{\mathrm{n}+1}-\mathrm{Br}+\mathrm{CBr}_{3}$.

$\mathrm{CBr}_{3} \mathrm{M}_{\mathrm{n}+1}+\mathrm{Br}-\mathrm{CBr}_{3} \longrightarrow \mathrm{CBr}_{3} \mathrm{M}_{\mathrm{n}+1}-\mathrm{Br}+\mathrm{CBr}_{3}$.

\section{Termination:}

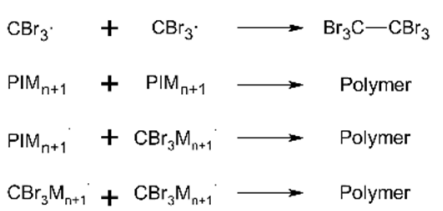

Figure 1. Schematic graph of UV-induced cotelomerization process with different type I radical photoinitiators.

Table 2. Compositions of monomers, telogen, and photoinitiators for UV-induced cotelomerization process.

\begin{tabular}{|c|c|c|c|c|c|}
\hline \multirow{2}{*}{ Cotelomer Acronym } & \multicolumn{3}{|c|}{ Monomers (wt\%) } & \multicolumn{2}{|c|}{ PI } \\
\hline & BA & AA & APB & Symbol & $\mathrm{mmol}^{*}$ \\
\hline BAA-127-15 & & & & & 15 \\
\hline BAA-127-30 & & & & O127 & 30 \\
\hline BAA-127-45 & & & & & 45 \\
\hline BAA-184-15 & & & & & 15 \\
\hline BAA-184-30 & & & & O184 & 30 \\
\hline BAA-184-45 & & & & & 45 \\
\hline BAA-819-15 & & & & & 15 \\
\hline BAA-819-30 & & & & O819 & 30 \\
\hline BAA-819-45 & & & & & 45 \\
\hline BAA-TPO-15 & 91.5 & 7.5 & 1 & & 15 \\
\hline BAA-ТPO-30 & & & & ОТРО & 30 \\
\hline BAA-TPO-45 & & & & & 45 \\
\hline
\end{tabular}


Table 2. Cont.

\begin{tabular}{cccccc}
\hline \multirow{2}{*}{ Cotelomer Acronym } & \multicolumn{3}{c}{ Monomers (wt\%) } & \multicolumn{2}{c}{ PI } \\
\cline { 2 - 5 } & BA & AA & APB & Symbol & mmol * \\
\hline BAA-TPOL-15 & & & & 15 \\
BAA-TPOL-30 & & & OTPOL & 30 \\
BAA-TPOL-45 & & & & 45 \\
BAA-2100-15 & & & O2100 & 15 \\
BAA-2100-30 & & & & 30 \\
BAA-2100-45 & & & & 45 \\
\hline
\end{tabular}

* per $50 \mathrm{~g}$ of monomer mixture.

The cotelomerization processes were carried out at $20^{\circ} \mathrm{C}$ for $30 \mathrm{~min}$ in a glass reactor $(250 \mathrm{~mL})$, equipped with a mechanical stirrer and thermocouple, in the presence of argon as inert gas. A mixture of monomers $(50 \mathrm{~g})$ was introduced into the reactor and purged with argon for $20 \mathrm{~min}$. A high-intensity UV lamp (UVAHAND 250, Dr. Hönle AG UV Technology, Gräfelting, Germany) as a UV radiation source was used and was placed perpendicularly to the side wall of the reactor. The UV irradiation inside the reactor $\left(15 \mathrm{~mW} / \mathrm{cm}^{2}\right)$ was controlled with UV-radiometer SL2W (UV-Design, Brachttal, Germany). The reactor was water-cooled (using room-temperature water).

At the beginning, the kinetics studies of the UV-induced cotelomerization process of BA, AA, and ABP (compositions in Table 2) were tested using a differential scanning calorimeter with a UV attachment (photo-DSC, DSC Q100, TA Instruments, New Castle, DE, USA; UV-light emitter Omnicure S2000; Excelitas Technologies, USA) at room temperature (isothermal measurement). Samples $(5 \mathrm{mg}$ ) were irradiated with UV in the range 320-390 nm with an intensity of $15 \mathrm{~mW} / \mathrm{cm}^{2}$ in an argon atmosphere. All DSC photopolymerization experiments were conducted in triplicate. The polymerization rate $\left(\mathrm{R}_{\mathrm{p}}, \% / \mathrm{s}\right)$ was calculated according to Equation (1), and the conversion of double bonds ( $\mathrm{p}$, $\%)$-according to Equation (2) and photoinitiation index $\left(\mathrm{I}_{\mathrm{p}}\right)$-was calculated according to Equation (3) [29].

$$
\begin{gathered}
\mathrm{R}_{\mathrm{p}}=\frac{\Delta \mathrm{H}_{\mathrm{t}} / \mathrm{dt}}{\mathrm{H}_{0}} \\
\mathrm{p}=\frac{\Delta \mathrm{H}_{\mathrm{t}}}{\mathrm{H}_{0}} \times 100 \% \\
\mathrm{I}_{\mathrm{p}}=\frac{\mathrm{R}_{\mathrm{p}}^{\max }}{\mathrm{t}_{\max }}
\end{gathered}
$$

where: $\mathrm{dH} / \mathrm{dt}$ - heat flow in the polymerization reaction; $\mathrm{H}_{0}$ - theoretical heat for the complete degree of conversion (for acrylates: $\Delta \mathrm{H}=78.0 \mathrm{~kJ} / \mathrm{mol}$ ); $\Delta \mathrm{H}_{\mathrm{t}}$-the reaction heat evolved at time t.

Then, the physicochemical properties of the BAA syrups and BAA cotelomers obtained after the bulk UV-induced cotelomerization process were examined.

Dynamic viscosity of the BAA syrups (BAA cotelomers with unreacted monomers) was measured at $25^{\circ} \mathrm{C}$ by means of a DV-II Pro Extra viscometer (spindle \#6, $50 \mathrm{rpm}$; Brookfield, New York, NY, USA). The solid content (SC) of the prepared syrups was determined using a Moisture Analyzer MA 50/1.X2.IC.A (Radwag, Radom, Poland). Samples (ca. $2 \mathrm{mg}$ ) were heated in aluminum scale pans at a temperature $105^{\circ} \mathrm{C}$ for $4 \mathrm{~h}$. The SC parameter was calculated according to Equation (4):

$$
\mathrm{SC}=\frac{\mathrm{m}_{2}}{\mathrm{~m}_{1}} \cdot 100\left(\mathrm{wt}^{\mathrm{o}} \%\right)
$$

where: $\mathrm{m}_{1}$-initial weight of a sample; $\mathrm{m}_{2}$-residual weight after an evaporation process.

Gel permeation chromatography (GPC) was used to determine the molecular masses $(\mathrm{Mw}, \mathrm{Mn})$ and polydispersity (PDI) of the BAA cotelomers (post-reaction mixtures were dried at $140{ }^{\circ} \mathrm{C}$ for $4 \mathrm{~h}$ before the test to remove unreacted monomers); the GPC apparatus 
contained the refractive index detector (Merck Lachrom RI L-7490, Abingdon, UK), pump (Merck Hitachi Liquid Chromatography L-7100, Abingdon, UK) and interface (Merck Hitachi Liquid Chromatography D-7000, Abingdon, UK), and the Shodex Ohpak SB-806 MQ column with Shodex Ohpak SB-G pre-column (Merck Hitachi Liquid Chromatography L-7100, Abingdon, UK). The GPC tests were performed using polystyrene standards (Fluka and Polymer Standards Service GmbH, Mainz, Germany) in tetrahydrofurane.

\subsection{Preparation and Characterization of Obtained Pressure-Sensitive Adhesives (PSAs)}

The adhesive compositions for the preparation of PSAs were compounded using BAA syrups (90 wt \%), HTB crosslinking agent $(7.5 \mathrm{wt} \%)$, and TPOL photoinitiator (2.5 $\mathrm{wt} \%)$. The PSA components were mixed using a high-speed mechanical mixer (T10 Basic UltraTurrax, IKA, Königswinter, Germany). The compositions were applied onto a polyester foil $(50 \mu \mathrm{m})$ and UV-irradiated using a medium-pressure mercury lamp (UV-ABC; Hönle UV-Technology, Gräfelfing, Germany). The UV doses were $4 \mathrm{~J} / \mathrm{cm}^{2}$. The UV exposition was controlled with a radiometer (Dynachem 500; Dynachem Corp., Westville, IL, USA). The basis weight of samples was $60 \mathrm{~g} / \mathrm{m}^{2}$. Preparation steps of PSAs are graphically presented in Figure 2.
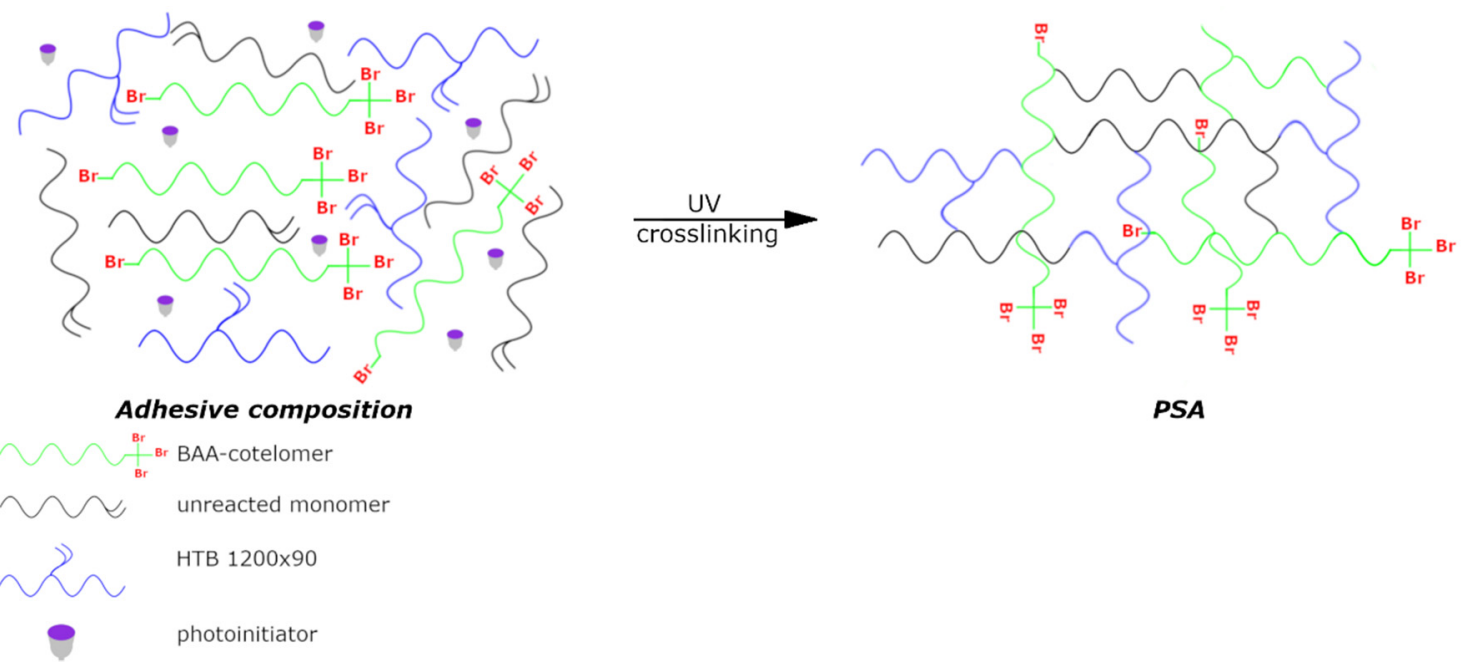

PSA

Figure 2. Preparation steps of the pressure-sensitive adhesives from BAA cotelomers.

Self-adhesive tests (adhesion to a steel, tack, and cohesion at $20^{\circ} \mathrm{C}$ and $70{ }^{\circ} \mathrm{C}$ ) were performed at $23 \pm 2{ }^{\circ} \mathrm{C}$ and $50 \pm 5 \%$ relative humidity. Adhesion is defined as the force value required to remove pressure-sensitive material from a stainless-steel plate; the removal proceeded at an angle of $180^{\circ}$ with a speed of $300 \mathrm{~mm} / \mathrm{min}$. Adhesion to a steel substrate was tested according to AFERA standards (Association des Fabricants Europe'ens de Rubans Auto-Adhe'sifs), i.e., AFERA 5001. Tack is characterized by a force value required to separate the stainless-steel plate and adhesive tape applied under low pressure for $0.5 \mathrm{~s}$. The tack measurements were performed according to AFERA 5015. The mentioned tests were carried out with the strength machine Zwick Rolell Z010 (Zwick/Roell, Ulm, Germany). Cohesion (i.e., static shear adhesion) describes the time needed to shear off the adhesive tape sample (under load of $1 \mathrm{~kg}$ ) from the defined steel surface. The cohesion tests were performed according to FINAT FTM 8. These parameters were evaluated using three samples of each adhesive film.

Differential scanning calorimetry (DSC Q100, TA Instr., New Castle, DE, USA) was used to determine the glass transition temperature $\left(\mathrm{T}_{\mathrm{g}}\right)$ values of the UV-crosslinked PSAs. Hermetic aluminum DSC pans were used and samples (ca. $10 \mathrm{mg}$ ) were analyzed from $-80^{\circ} \mathrm{C}$ to $250{ }^{\circ} \mathrm{C}$ (heating rate of $10^{\circ} \mathrm{C} / \mathrm{min}$ ). 


\section{Results}

\subsection{Kinetics Study of Photo-Cotelomerization Process}

Among the described photopolymerization processes, two general types can be distinguished, namely processes taking place in thin or thick layers. Relatively few publications have dealt with bulk photopolymerization processes with mechanically mixed monomers $[18,30]$. To the best of the authors' knowledge, this publication is the first to describe the effect of the type (and amount) of radical photoinitiator on the bulk photocotelomerization process of acrylic monomers. So far, there is a general agreement on the division into two main groups of type I photoinitiators (HPs and APOs), namely, HPs are dedicated to thin films (surface photocrosslinking), and APOs are more suitable for the photopolymerization of thick layers [21]. However, the influence of photoinitiators on UV-induced cotelomerization processes of acrylic monomers has not been investigated. A characteristic property of the process is the presence of radicals from the photolysis of telogen in the system (apart from the radicals derived from the photoinitiator photolysis and the resulting monomer radicals and macroradicals). Additionally, there are more of these radicals in the system compared to those coming from the photoinitiator. Some of the radical reactions are outlined in Figure 1. The results of the kinetics studies are presented in Figure 3 (photo-cotelomerization rate, $R_{p}$ and monomers conversion, $p$ ).

The UV-induced cotelomerization reaction without photoinitiator (brown line) ran at a very slow rate (ca. $0.1 \% / \mathrm{s}$ ) and slowed down after about $400 \mathrm{~s}$ of UV-irradiation. As can be seen, as the photoinitiator content increased, the reaction rate $\left(R_{p}\right)$ values increased. Interestingly, three characteristic areas could be marked on the graphs showing the reaction rate. The first area related to the $\mathrm{R}_{\mathrm{p}}$ in systems with O819 and OTPO photoinitiators, where the $R_{p}$ values were highest and increased from ca. 1 to $1.6 \% / \mathrm{s}$ with the PI dose. The second area was for systems with OTPOL and O2100 photoinitiators, where $R_{p}$ values ranged from 0.3 to $0.5 \% / \mathrm{s}$ at the lowest PI dose and only slightly increased to about $0.6 \% / \mathrm{s}$ at the highest PI dose. As is known, the photoinitiator O2100 contains mainly OTPOL ( $95 \mathrm{wt} \%$ ); therefore, the differences between the two systems were not large, and they were revealed only at the lowest dose of PI $(15 \mathrm{mmol})$. The reaction rate was also very similar at higher PI concentrations ( 30 or $45 \mathrm{mmol}$ ). The third region relates to the photo-cotelomerization rate in HP systems, for which the reaction rate was two or three times higher than in the system without any photoinitiator (i.e., 0.2 or $0.3 \% / \mathrm{s}$ ), and it increased indefinitely with the concentration of the photoinitiator. However, the reaction rates were very low compared to systems with O819 or OTPO.
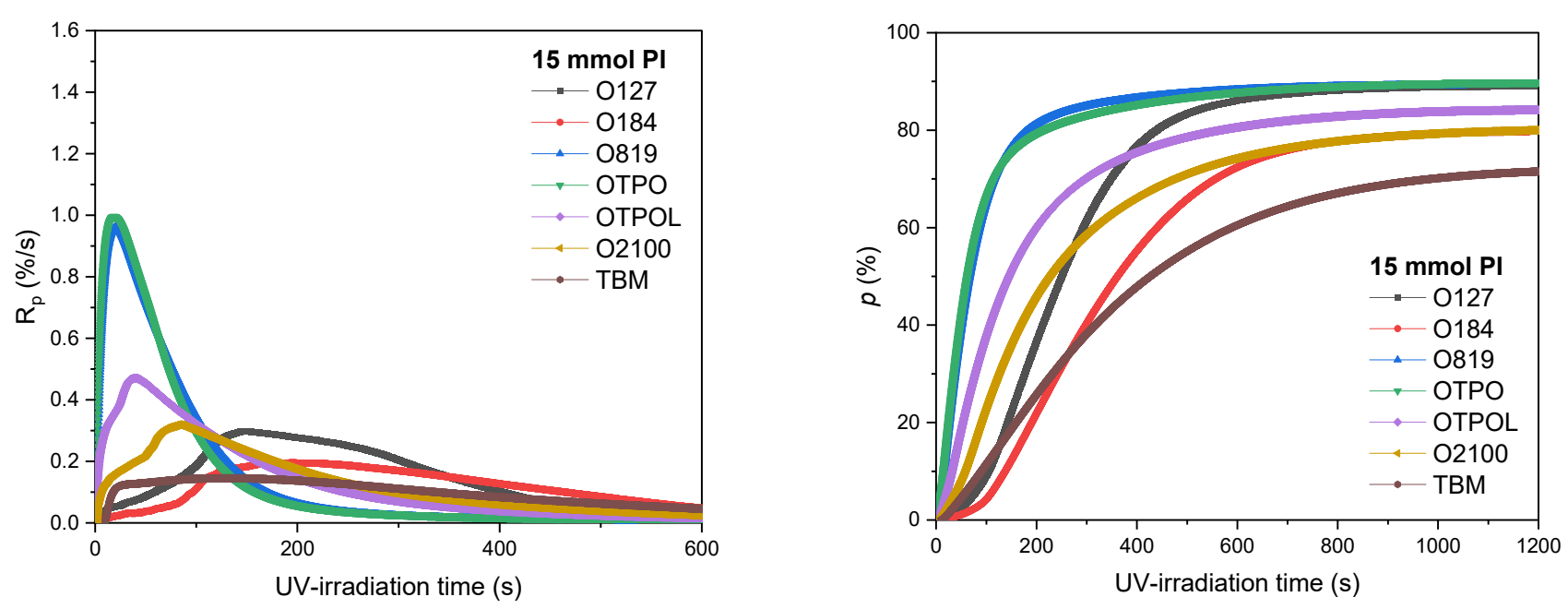

Figure 3. Cont. 

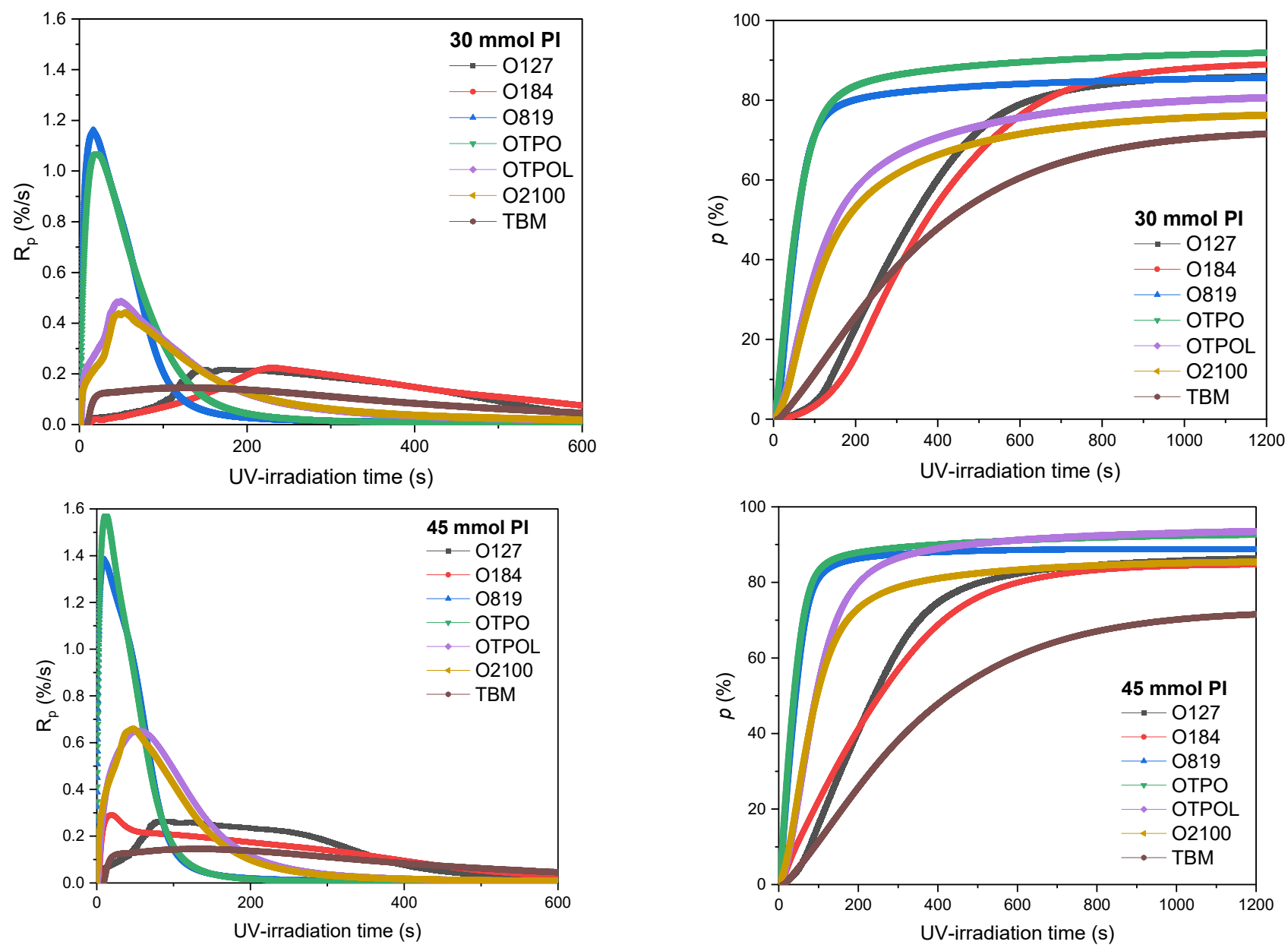

Figure 3. Kinetics parameters of $\mathrm{BA}, \mathrm{AA}$, and $\mathrm{ABP}$ photo-cotelomerization process in the presence of TBM as a chain transfer agent $\left(\mathrm{I}_{0}=15 \mathrm{~mW} / \mathrm{cm}^{2} ; 320-390 \mathrm{~nm}\right) ; \mathrm{R}_{\mathrm{p}}$-reaction rate; $\mathrm{p}$-conversion of double bonds.

Moreover, some delay in the initiation of reactions in HP systems can be observed, especially at their low concentration. The maximum rate of reaction was achieved after about $150 \mathrm{~s}$ of exposure to UV for doses of 15 or $30 \mathrm{mmol}$ of HPs, while for the system with APOs-after just a few seconds. In general, the monomer conversion exceeded $70 \%$ despite the slow reaction rates in some systems. The monomer conversion in the reference sample (without PI) was $72 \%$ after $1200 \mathrm{~s}$ of UV-irradiation during the photo-DSC test (without mixing of monomers mixture). High monomer conversions were obtained in the O819 and OTPO systems (90-93\%), corresponding to the highest values of reaction rates, and high conversion values (over $80 \%$ ) were received after 200 s of irradiation. OTPOL was second in terms of the speed of achieving the highest possible monomer conversion (80-94\%), and HP was third (although, at $30 \mathrm{mmol} \mathrm{PI}$, the final monomer conversion value was higher than for the OTPOL-based samples). The relatively high monomer conversion in the $\mathrm{HP}$-based samples, despite the slow reaction rate, resulted from keeping the reaction rate relatively constant and high $(0.2-0.3 \% / \mathrm{s})$ for a long period of exposure to light (even above $400 \mathrm{~s}$ ). On the other hand, in samples with APOs, the reaction was rapidly inhibited (after $100 \mathrm{~s}$ in the case of O819 and OTPO and 200-300 s in the case of OTPOL-based samples) as a consequence of the viscosity increase in the polymerizing system. It has been confirmed by the obtained results, as well as by the calculation of initiation efficiency $\left(\mathrm{I}_{\mathrm{p}}\right)$, that the efficiency of APOs in the photo-cotelomerization process was higher than that of HPs. The results are presented in Figure 4. 


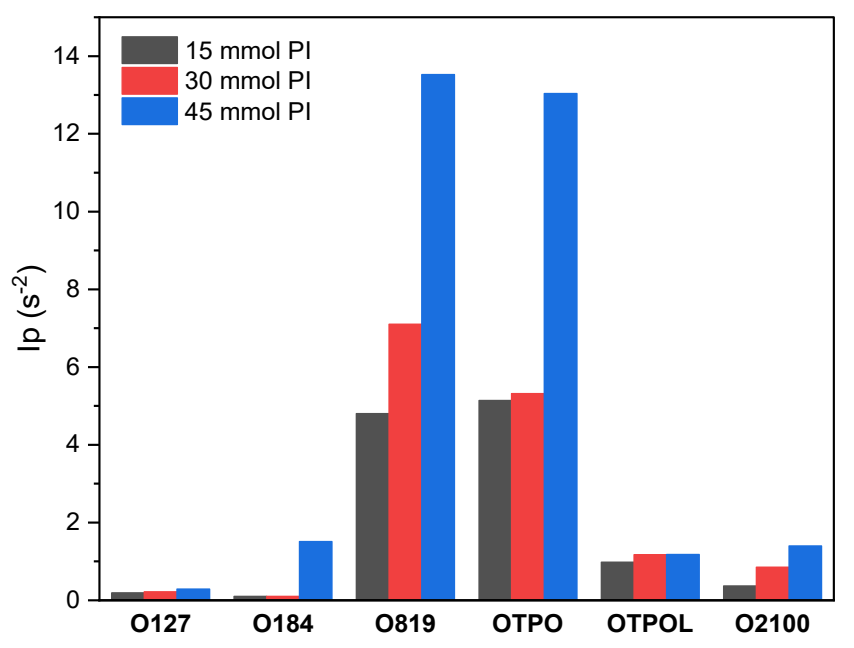

Figure 4. Initiation efficiency $\left(I_{p}\right)$ of the radical photoinitiators used for photo-cotelomerization processes of BA, AA, and ABP with TBM.

The initiation efficiency $\left(I_{p}\right)$ of the radical PIs increased with their concentration in the system, and extremely high values of $\mathrm{I}_{\mathrm{p}}$ were obtained at $45 \mathrm{mmol}$ of $\mathrm{O} 819$ and OTPO. The order of PI efficiency was as follows: O819 > OTPO > OTPOL > O2100 > O127 > O184. Surprisingly, the mixture of OTPOL with the most effective photoinitiator O819 (i.e., O2100) was characterized by worse properties than pure OTPOL. It might be caused by the effect of too many radicals and different types of radicals in the system, which leads to their recombination or extinction of excited states in the presence of tribromomethane and bromine radicals (resulting from TBM).

\subsection{Properties of BAA Syrups and Cotelomers}

The results of dynamic viscosity and solid content (SC) tests for the obtained BAA cotelomers solutions (BAA syrups) with different kinds and contents of type I radical photoinitiators are presented in Figure 5.

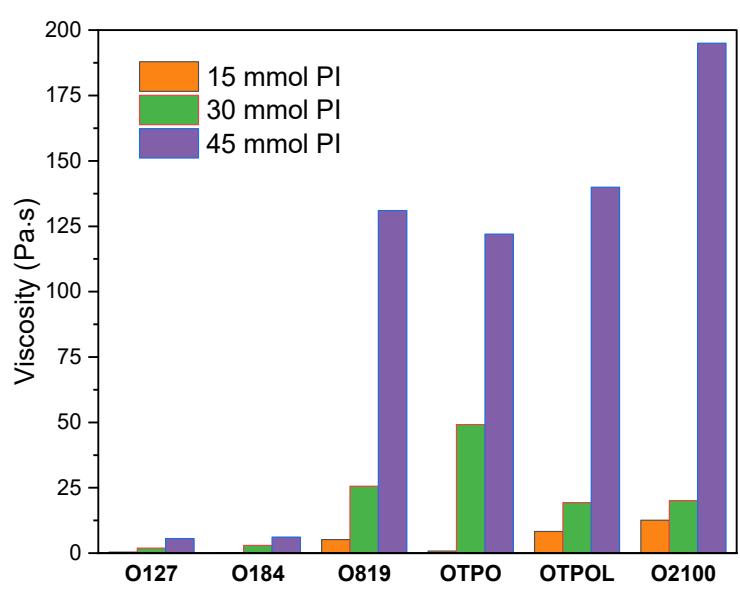

(a)

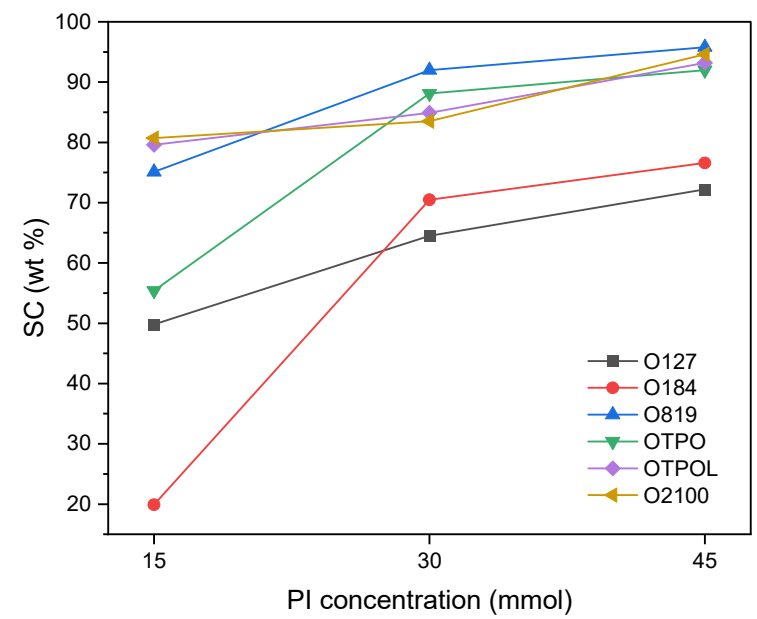

(b)

Figure 5. Viscosity (a) and solid content (b) of obtained BAA syrups.

As can been seen, the viscosity and SC values increased with the amount of photoinitiator used in the reaction. However, HP-based syrups exhibited significantly lower viscosity values (from 0.2 to $6.1 \mathrm{~Pa} \cdot \mathrm{s}$ ) than APO-based products (from 5 to $185 \mathrm{~Pa} \cdot \mathrm{s}$ ). The syrups with a viscosity below $3 \mathrm{~Pa} \cdot \mathrm{s}$ (BAA-127-15, BAA-127-30, and BAA-184-15) are not suitable 
for coating and forming thin adhesive films (PSAs) from a practical point of view. The SC values were also relatively low for the mentioned samples, especially for BAA-127-15 and BAA-184-15 (49.9 $\mathrm{wt} \%$ and $19.9 \mathrm{wt} \%$, respectively); this confirms the lowest initiation efficiency by these photoinitiators in the tested monomers system. An additional amount of increase in HP-type photoinitiators (up to $45 \mathrm{mmol}$ ) only slightly increased the viscosity (ca. $6 \mathrm{~Pa} \cdot \mathrm{s}$ ) and the SC values (72 and $76 \mathrm{wt} \%$, respectively). In contrast with APO-type PI samples, increasing the content of PI (up to $45 \mathrm{mmol}$ ) caused a significant increase in viscosity of syrups (viscosity above $100 \mathrm{~Pa} \cdot \mathrm{s}$; the samples were not suitable for coating at room temperature but—as with typical hot melt adhesives-had to be coated after heating). An extremely high viscosity value (185 Pa.s) was achieved for the sample BAA-2100-45 (with $45 \mathrm{mmol}$ of Omnirad 2100). More radicals were formed in this system and the SC value reached $96 \mathrm{wt} \%$. BAA syrups with APO-type PI, even with a low amount of PI (15 mmol), showed high SC values (75-81 wt $\%$ ) and suitable coating viscosities (5-12 Pa.s). The BAA-TPO- 15 sample ( $20 \mathrm{wt} \%$ of SC) is an exception confirming our previous research (for systems without telogen) [18]. It was noted that the highest SC values were obtained for BAA-819-45 (96 wt\%). As we previously reported, the type and amount of PIs have a significant influence on the free radical bulk photopolymerization process (without telogen) of selected (meth)acrylate monomers. It has been proven that the acrylic syrups prepared using APO photoinitiators exhibited a higher viscosity and SC than samples with HPs did, as well as average molecular weights [18]. In the case of the UV-induced cotelomerization process, it turns out that samples with APOs showed lower molecular weights $\left(M_{n}\right.$ and $\left.M_{w}\right)$ than samples with HPs did. The molecular weights and polydispersity of BAA-cotelomers are presented in Table 3. Higher molecular weights $\left(\mathrm{M}_{\mathrm{n}}\right.$ and $\mathrm{M}_{\mathrm{W}}$ values) were exhibited for samples with HPs $\left(M_{n}=19,790-21,530 \mathrm{~g} / \mathrm{mol}\right.$ and $\left.\mathrm{M}_{\mathrm{w}}=30,570-34,400 \mathrm{~g} / \mathrm{mol}\right)$ than with APOs $\left(M_{n}=17,250-19,390 \mathrm{~g} / \mathrm{mol}\right.$ and $\left.\mathrm{M}_{\mathrm{w}}=26,320-31,120 \mathrm{~g} / \mathrm{mol}\right)$. Generally, the average molecular weights decreased with the amount of photoinitiator (high concentration of PI gives a high radical count and leads to the production of multiple chain polymerization reactions).

Table 3. Molecular weights and polydispersity of BAA-cotelomers.

\begin{tabular}{cccc}
\hline Cotelomer Symbol & $\mathbf{M}_{\mathbf{n}}(\mathbf{g} / \mathbf{m o l})$ & $\mathbf{M}_{\mathbf{w}}(\mathbf{g} / \mathbf{m o l})$ & PDI \\
\hline BAA-127-15 & 21,530 & 33,770 & 1.57 \\
BAA-127-30 & 20,520 & 32,930 & 1.61 \\
BAA-127-45 & 20,100 & 30,570 & 1.52 \\
BAA-184-15 & 21,010 & 34,400 & 1.64 \\
BAA-184-30 & 21,060 & 32,540 & 1.54 \\
BAA-184-45 & 19,790 & 30,670 & 1.55 \\
BAA-819-15 & 18,150 & 28,440 & 1.57 \\
BAA-819-30 & 17,650 & 27,090 & 1.53 \\
BAA-819-45 & 17,460 & 26,930 & 1.54 \\
BAA-TPO-15 & 19,390 & 31,120 & 1.60 \\
BAA-TPO-30 & 18,210 & 27,190 & 1.49 \\
BAA-TPO-45 & 17,460 & 26,430 & 1.51 \\
BAA-TPOL-15 & 17,500 & 28,670 & 1.64 \\
BAA-TPOL-30 & 18,260 & 27,450 & 1.50 \\
BAA-TPOL-45 & 17,250 & 26,320 & 1.53 \\
BAA-2100-15 & 19,100 & 28,990 & 1.52 \\
BAA-2100-30 & 18,940 & 28,620 & 1.51 \\
BAA-2100-45 & 17,970 & 27,450 & 1.53 \\
\hline
\end{tabular}

In contrast, the PDI values were very similar for all samples (1.5-1.6 a.u.). The low polydispersity index (as in polymers obtained by the ATRP method) demonstrated a nearunimodal molecular weight distribution. Additionally, it was due to the presence of the chain transfer agent (tetrabromomethane, TBM) and its interaction with photoinitiators. The several types of radicals were formed (from TBM and PIs) during UV-irradiation. The possible paths of UV-induced cotelomerization reaction are shown in Figure 1. The content 
of linear polymers in the system (adhesive composition contains linear BAA cotelomers, unreacted monomers, and HTB) and the average molecular weights of BAA cotelomers should influence the adhesive properties (adhesion to steel and tack) and the cohesion of the prepared PSAs. Generally, there were more linear polymers (higher SC values) with lower molecular weights in APO systems, and, conversely, fewer linear polymers but with higher molecular weights were in HP systems. The dependence of the adhesion to steel on the solids content (SC may be the same as monomer conversion [18]) is shown in Figure 6. The graph demonstrates the results only for samples BAA-819 (prepared using PI with the highest $I_{p}$ values, Figure 4) and BAA-TPOL (PI with average $I_{p}$ values). The adhesion values were higher for PSAs based on BAA-TPOL than BAA-819 and they decreased with the PI concentration (from 9.5 to $5.5 \mathrm{~N} / 25 \mathrm{~mm}$ ). The $\mathrm{SC}$ values were slightly lower for BAA-TPOL samples (80-94 $\mathrm{wt} \%$ ) than for the PI samples with the highest initiation efficiency (75-96 wt\%). The SC values increased (higher content of linear polymers) as the adhesion values decreased (for both considered systems). Both systems (BAA-819 and BAA-TPOL) were characterized by very similar values of $M_{n}$ (ca. $17,000 \mathrm{~g} / \mathrm{mol}$ ) and $M_{w}$ $(27,000 \mathrm{~g} / \mathrm{mol}$; Table 3).

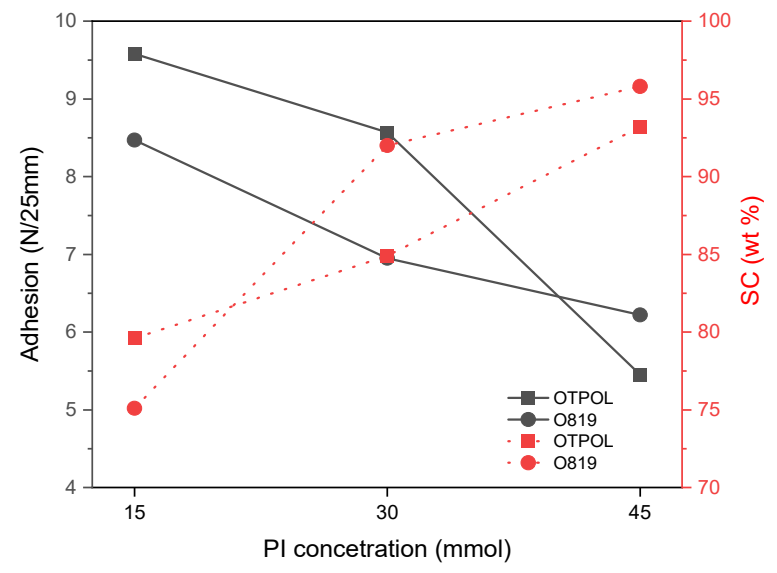

Figure 6. Dependence of adhesion to steel and solid content on photoinitiator concentration.

However, systems with a higher SC value (higher content of linear cotelomers with very similar molecular weights) include more Br-terminated chains (according to the telomerization mechanism, the ends of the formed telomer contain fragments of telogen [28]). This likely results in less adhesion to the substrate (nonpolar cotelomer chain ends). The influence of various types and concentrations of PIs on the adhesion is shown in Figure 7).

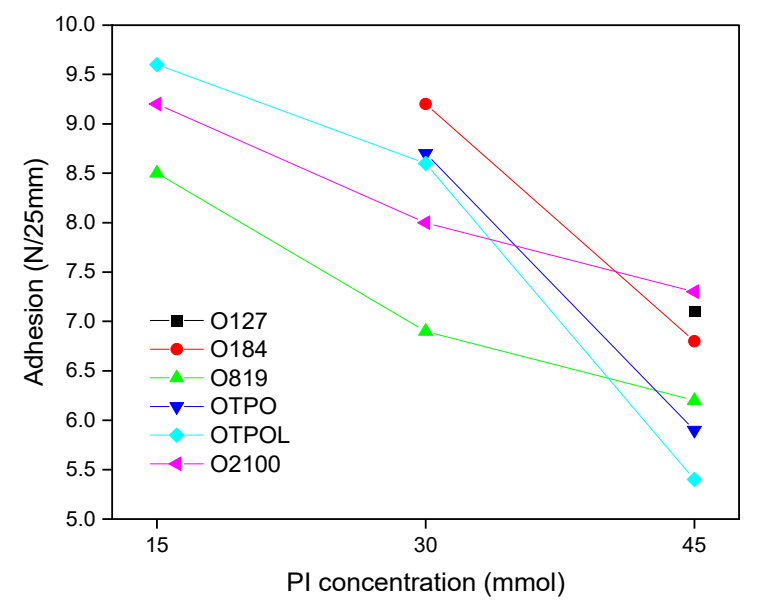

Figure 7. Adhesion to steel of PSA based on BAA cotelomers prepared using different types and concentrations of PIs. 
Regardless of the PI type, with the increase in PI concentration (increase in the SC value), the adhesion of prepared PSAs decreased. The highest values of adhesion to steel were obtained for PSAs based on BAA cotelomers with the lowest dose of photoinitiator (15 mmol). The best result of adhesion was received for the PSA from BAA-TPOL-15 syrup $(9.7 \mathrm{~N} / 25 \mathrm{~mm})$. A high result of adhesion $(9.4 \mathrm{~N} / 25 \mathrm{~mm})$ was also noted for PSA with photoinitiator $\mathrm{O} 2100$. Interestingly, high adhesion values $(9.2 \mathrm{~N} / 25 \mathrm{~mm}$; PI concentration $30 \mathrm{mmol}$ ) were obtained for PSA prepared with the least effective photoinitiator O184 (HPs-type). However, the SC value of the BAA-184-30 syrup was 70\%. It can be concluded that the SC value in the obtained syrups had a key influence on the adhesion to steel. The tack values also decreased with the concentration of photoinitiator. The results of tack measurements are shown in Table 4 . The tack values were generally lower than the adhesion values (typical for PSA).

Table 4. Cohesion and tack values of PSAs based on BAA cotelomers.

\begin{tabular}{cccc}
\hline & \multicolumn{2}{c}{ Cohesion [h] } & Tack (N) \\
\cline { 2 - 3 } PSA Symbol & $\mathbf{2 0}{ }^{\circ} \mathbf{C}$ & $\mathbf{7 0}{ }^{\circ} \mathbf{C}$ & nd \\
\cline { 2 - 4 } BAA-127-15 & nd & nd & nd \\
BAA-127-30 & nd & nd & $2.1 \pm 0.2$ \\
BAA-127-45 & $100 \pm 3$ & $72 \pm 2$ & nd \\
BAA-184-15 & nd & nd & $3.0 \pm 0.3$ \\
BAA-184-30 & $100 \pm 4$ & $72 \pm 1$ & $2.5 \pm 0.1$ \\
BAA-184-45 & $100 \pm 5$ & $72 \pm 2$ & $6.5 \pm 0.3$ \\
BAA-819-15 & $100 \pm 3$ & $72 \pm 2$ & $5.2 \pm 0.3$ \\
BAA-819-30 & $14 \pm 0.5$ & $3 \pm 0.2$ & $2.4 \pm 0.2$ \\
BAA-819-45 & $5 \pm 0.5$ & $0.1 \pm 0.02$ & nd \\
BAA-TPO-15 & nd & nd & $7.1 \pm 0.4$ \\
BAA-TPO-30 & $100 \pm 5$ & $72 \pm 3$ & $5.3 \pm 0.2$ \\
BAA-TPO-45 & $11 \pm 0.3$ & $2 \pm 0.2$ & $3.2 \pm 0.1$ \\
BAA-TPOL-15 & $100 \pm 6$ & $72 \pm 3$ & $3.1 \pm 0.2$ \\
BAA-TPOL-30 & $100 \pm 4$ & $72 \pm 4$ & $2.5 \pm 0.2$ \\
BAA-TPOL-45 & $1 \pm 0.2$ & $0.3 \pm 0.2$ & $5.1 \pm 0.4$ \\
BAA-2100-15 & $100 \pm 2$ & $72 \pm 3$ & $5.0 \pm 0.3$ \\
BAA-2100-30 & $100 \pm 5$ & $72 \pm 3$ & $2.5 \pm 0.1$ \\
BAA-2100-45 & $2 \pm 0.2$ & $0.6 \pm 0.2$ & \\
\hline
\end{tabular}

nd-no data.

The highest tack values were recorded for samples based on BAA-TPO-30 and BAA819-15 (7.1 N and $6.5 \mathrm{~N}$, respectively). Interestingly, almost all prepared PSAs were characterized by excellent cohesion at $20^{\circ} \mathrm{C}(100 \mathrm{~h})$ and $70{ }^{\circ} \mathrm{C}(72 \mathrm{~h})$. Only samples with low tack values (usually ca. $5 \mathrm{~N}$ or less, with APO-type PI concentration-45 mmol) did not wet the steel surface sufficiently during the cohesion test. Additionally, these samples obtained a low cohesion result. Interestingly, samples from HP-type PIs (O127 and O184), even at a low tack value ( 2 or $3 \mathrm{~N}$ ), were characterized by very high cohesion due to the presence of cotelomers with higher molecular weights compared to the PSA with APOs (Table 2). Molecular weight values and $\mathrm{T}_{\mathrm{g}}$ values are critical for the use of a polymer as a PSA. The $\mathrm{T}_{\mathrm{g}}$ values for selected PSAs (with $45 \mathrm{mmol}$ of PI) are shown in Figure 8.

As can be seen, PSAs possessed the $\mathrm{T}_{\mathrm{g}}$ range from ca. $-33^{\circ} \mathrm{C}$ (PSAs with HPs) to ca. $-37^{\circ} \mathrm{C}$ (PSAs with APOs). It is known that PSAs should have a $\mathrm{T}_{\mathrm{g}}$ of about -15 to $-5^{\circ} \mathrm{C}$ or less, and acrylic PSA possesses a $\mathrm{T}_{\mathrm{g}}$ range from $-40{ }^{\circ} \mathrm{C}$ to $-60^{\circ} \mathrm{C}$. The $\mathrm{T}_{\mathrm{g}}$ is a function of molecular weight $\left(\mathrm{M}_{\mathrm{n}}\right)$, as well as other chemical and macromolecular characteristic, e.g., chemical composition and crosslink density [31]. It should be noted that the BAA cotelomers with HPs (45 mmol) exhibited higher $M_{n}$ values (ca. 20,000 g/mol; Table 3) than the BAA with APOs (ca. 17,000 g/mol). Thus, the PSAs based on the BAA-HPs exhibited higher $\mathrm{T}_{\mathrm{g}}$ values (less chains mobility) than samples with APOs. Additionally, the research shows that PSA with HPs was characterized by a higher crosslinking density (lower SC value, ca. $70 \mathrm{wt} \%$ ) than samples with APOs (ca. $90 \mathrm{wt} \%$ ); therefore, PSA-HPs possessed a 
higher $\mathrm{T}_{\mathrm{g}}$. It is known that crosslinking reduces chain mobility and, thus, increases the $\mathrm{T}_{\mathrm{g}}$. However, it can be concluded that the differences in $\mathrm{T}_{\mathrm{g}}$ values were not significantly large. This is because the obtained PSAs, although they differed in crosslink density, chemically contained the same amount of polar monomer (AA) and were crosslinked in the same way (using the same amount of HTB and the same UV dose). These factors would have a greater influence on the difference in $\mathrm{T}_{\mathrm{g}}$ values.

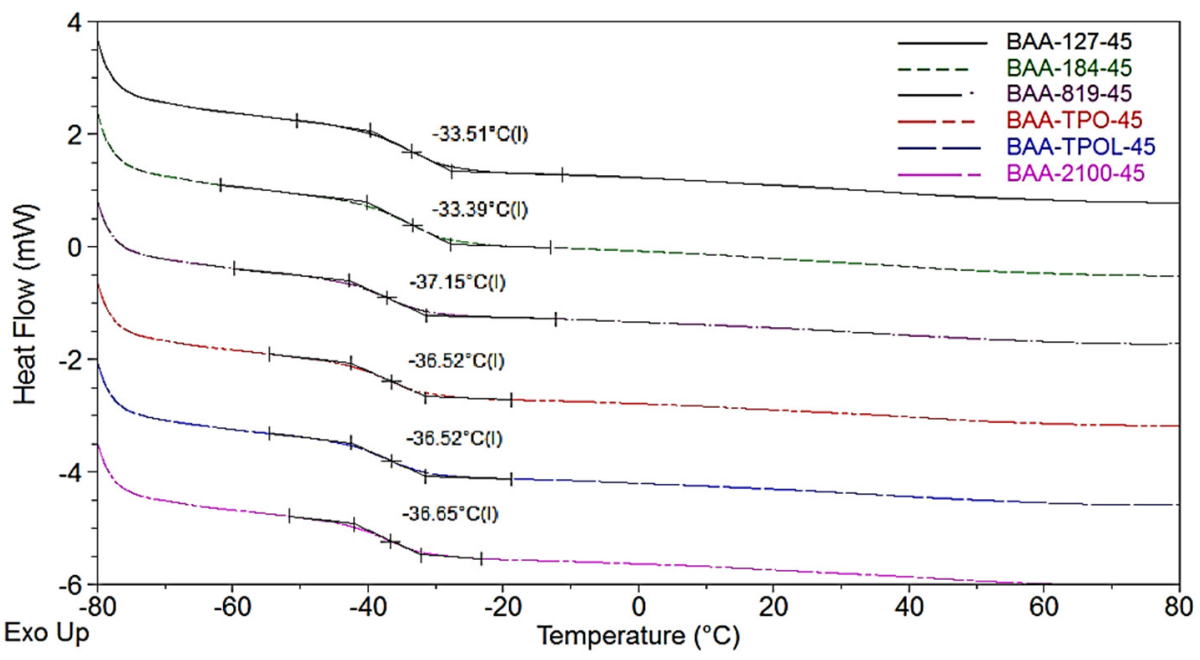

Figure 8. $\mathrm{T}_{\mathrm{g}}$ values of PSAs based on BAA cotelomer.

\section{Conclusions}

In this paper, a new preparation method (i.e., UV-induced cotelomerization process) of solvent-free acrylic pressure-sensitive adhesives was presented and the influence of type I radical photoinitiators (HPs and APOs) on the kinetic parameters of the process was investigated. Moreover, the physico-chemical properties of cotelomer syrups and self-adhesive features of prepared PSAs were tested. It was revealed that APOs were significantly more efficient in the cotelomerization process than HPs were. The order of PI efficiency has been proven: O819 > OTPO > OTPOL > O2100 > O127 > O184. A high monomer conversion (the solid content) was obtained even at the lowest PI concentration (15 mmol) in systems with O819 (81 wt\%) and OTPO (75 wt\%). It was also found that cotelomer syrups based on APOs were characterized by considerable higher viscosity values than HP-based syrups. Moreover, the APO-based syrups contained more linear polymers (high SC values) with lower molecular weights than systems with HPs. These have been found to be key factors in the self-adhesive properties of PSAs. Higher adhesion and tack values were observed at low SC (55-80 wt\%) and low-molecular-weight cotelomers (i.e., with APOs). A significant reduction in adhesion and tack was observed with increasing SC values ( $>80 \mathrm{wt} \%)$. It can be concluded that the vast majority of PSAs showed excellent cohesion $(>72 \mathrm{~h})$, regardless of the SC value or the molecular weights of the cotelomers. However, the high cohesion is most likely due to the method of crosslinking itself and the selection of the monomer and the UV dose. The methods of adhesive composition modification (with hydroxyl-terminated polybutadiene) itself and by UV-crosslinking were correct and noteworthy. The SC values and molecular weight had a great impact on $\mathrm{T}_{\mathrm{g}}$ values of prepared PSAs as well. The cotelomers with higher SC values and lower $\mathrm{M}_{\mathrm{n}}$ gave PSAs with lower $\mathrm{T}_{\mathrm{g}}$ values.

Author Contributions: Conceptualization, A.K. (Agnieszka Kowalczyk) and M.W.; methodology, A.K. (Agnieszka Kowalczyk) and M.W.; investigation, M.W., A.K. (Agnieszka Kowalczyk), B.S. and A.K. (Agata Kraśkiewicz); writing-review and editing, A.K. (Agnieszka Kowalczyk) and M.W.; visualization, M.W. and A.K. (Agnieszka Kowalczyk); supervision, A.K. (Agnieszka Kowalczyk) and M.W. All authors have read and agreed to the published version of the manuscript. 
Funding: This research received no external funding.

Institutional Review Board Statement: Not applicable.

Informed Consent Statement: Not applicable.

Data Availability Statement: The data presented in this study are available on request from the corresponding author.

Conflicts of Interest: The authors declare no conflict of interest.

\section{References}

1. Slota, J.; Kubit, A.; Trzepieciński, T.; Krasowski, B.; Varga, J. Ultimate Load-Carrying Ability of Rib-Stiffened 2024-T3 and 7075-T6 Aluminium Alloy Panels under Axial Compression. Materials 2021, 14, 1176. [CrossRef]

2. Satas, D. Handbook of Pressure Sensitive Adhesive Technology; Springer: Warwick, RI, USA, 1999; pp. 346-398.

3. Creton, C. Pressure-Sensitive Adhesives: An Introductory Course. MRS Bull. 2003, 28, 434-439. [CrossRef]

4. Brockmann, W.; Geiss, P.; Klingen, J.; Schröder, B. Adhesive Bonding: Materials, Applications and Technology; Wiley-VCH Verlag GmbH\&Co. KGaA: Weinheim, Germany, 2009; pp. 39-46.

5. Doyle, J.; Quinn, R. Adhesives: Types, Mechanics and Applications; Nova Science Publishers: New York, NY, USA, 2011 ; pp. 47-71.

6. Adams, R.D. Adhesive Bonding: Science, Technology and Applications; CRP Press: Abington, UK, 2007; p. 34.

7. Márquez, I.; Alarcia, F.; Velasco, J. Synthesis and Properties of Water-Based Acrylic Adhesives with a Variable Ratio of 2-Ethylhexyl Acrylate and n-Butyl Acrylate for Application in Glass Bottle Labels. Polymers 2020, 12, 428. [CrossRef] [PubMed]

8. Mapari, S.; Mestry, S.; Mhaske, S.T. Developments in pressure-sensitive adhesives: A review. Polym. Bull. 2021, 78, 4075-4108. [CrossRef]

9. Arunprasert, K.; Pornpitchanarong, C.; Rojanarata, T.; Ngawhirunpat, T.; Opanasopit, P.; Aumklad, P.; Patrojanasophon, P. Development and Evaluation of Novel Water-Based Drug-in-Adhesive Patches for the Transdermal Delivery of Ketoprofen. Pharmaceutics 2021, 13, 789. [CrossRef] [PubMed]

10. Back, J.H.; Kwon, Y.; Roldao, J.C.; Yu, Y.; Kim, H.; Gierchner, J.; Lee, W.; Kwon, M.S. Solvent-free acrylic pressure-sensitive adhesives via a visible-light driven photocatalytic radical polymerization without additives. Green Chem. 2020, 22, 8289-8297. [CrossRef]

11. Back, J.H.; Kwon, Y.; Kim, H.J.; Yu, Y.; Lee, W.; Kwon, M.S. Visible-light-curable solvent-free acrylic pressure-sensitive adhesives via photoredox-mediated radical polymerization. Macromolecules 2021, 26, 385. [CrossRef]

12. Baek, S.; Jang, S.; Lee, S.; Hwang, S. Effect of Chemical Structure of Acrylate Monomer on the Transparent Acrylic Pressure Sensitive Adhesives for Optical Applications. Polym. Korea 2014, 38, 682. [CrossRef]

13. Baek, S.; Jang, S.; Hwang, S. Preparation and adhesion performance of transparent acrylic pressure sensitive adhesives: Effects of substituent structure of acrylate monomer. Int. J. Adhes. Adhes. 2016, 64, 72-77. [CrossRef]

14. Beak, S.; Hwang, S. Preparation and adhesion performance of transparent acrylic pressure-sensitive adhesives containing menthyl acrylate. Polym. Bull. 2016, 73, 687-701. [CrossRef]

15. Beak, S.; Hwang, S. Eco-friendly UV-curable pressure sensitive adhesives containing acryloyl derivatives of monosaccharides and their adhesive performances. Int. J. Adhes. Adhes. 2016, 70, 110-113. [CrossRef]

16. Baek, S.; Jang, S.; Hwang, S. Construction and adhesion performance of biomass tetrahydro-geraniol-based sustainable/transparent pressure sensitive adhesives. J. Ind. Eng. Chem. 2017, 53, 429-434. [CrossRef]

17. Kim, J.; Shim, G.; Baek, D.; Back, J.; Jang, S.; Kim, H.; Choi, J.; Yeom, J. UV/UV step-curing of optically clear acrylate adhesives for mobile devices. Express Polym. Lett. 2019, 13, 794-805. [CrossRef]

18. Gziut, K.; Kowalczyk, A.; Schmidt, B. Free-radical bulk photopolymerization process as method of obtaining thermally curable structural self-adhesive tapes and effect of used type I photoinitiators. Polymers 2020, 12, 2191. [CrossRef]

19. Yagci, Y.; Jockusch, S.; Turro, N.J. Photoinitiated polymerization: Advances, challenges and opportunities. Macromolecules 2010, 43, 6245-6260. [CrossRef]

20. Dietliker, K.A. Compilation of Photoinitiators Commercially Available for UV Today; Sita Technology Ltd.: London, UK, 2002.

21. Green, W.A. Industrial Photoinitiators. A Technical Guide; CRP Press: New York, NY, USA, 2010; pp. 75-82.

22. Tehfe, M.A.; Dumur, F.; Graff, B.; Morlet-Savary, F.; Gigmes, D.; Fouasier, J.P.; Lalevée, J. Design of new type I and type II photoinitiators possessing highly coupled pyrene-ketone moieties. Polym. Chem. 2013, 4, 2313. [CrossRef]

23. Al Mousawi, A.; Garra, P.; Dumur, F.; Bui, T.T.; Goubard, F.; Toufaily, J.; Hamieh, T.; Gra, B.; Gigmes, D.; Fouasier, J.P.; et al. Novel Carbazole Skeleton-Based Photoinitiators for LED Polymerization and LED Projector 3D Printing. Molecules 2017, $22,2143$. [CrossRef]

24. Nazir, R.; Danilevicius, P.; Gray, D.; Farsani, M.; Gryko, D.T. Push-Pull Acylo-Phosphine Oxides for Two-Photon-Induced Polymerization. Macromolecules 2013, 46, 7239-7244. [CrossRef]

25. Dietlin, C.; Trinh, T.T.; Schweizer, S.; Graff, B.; Morlet-Savary, F.; Noirot, P.A.; Lelevée, J. New Phosphine Oxides as High Performacne Near-UV Type I Photoinitiators of Radical Polymerization. Molecules 2020, 25, 1671. [CrossRef]

26. Eren, T.N.; Lalevéel, J.; Avci, D. Water soluble polymeric photoinitiator for dual-curing of acrylates and methacrylates. J. Photochem. Photobiol. A Chem. 2020, 389, 112288. [CrossRef] 
27. Kowalczyk, A.; Weisbrodt, M.; Schmidt, B.; Gziut, K. Influence of Acrylic Acid on Kinetics of UV-Induced Cotelomerization Process and Properties of Obtained Pressure-Sensitive Adhesives. Materials 2020, 13, 5661. [CrossRef]

28. Boutevin, B. From telomerization to living radical polymerization. J. Polym. Sci. Part. A Polym. Chem. 2000, 38, 3235-3243. [CrossRef]

29. Clark, S.C.; Hill, D.J.T.; Hoyle, C.E.; Miller, C.W.; Shao, L.Y. N-Substituent effect of maleimides on acrylate polymerization initiated by three-component systems. Polym. Int. 2003, 52, 1701-1710. [CrossRef]

30. Gziut, K.; Kowalczyk, A.; Schmidt, B.; Kowalczyk, K.; Weisbrodt, M. Epoxy-Based Structural Self-Adhesive Tapes Modified with Acrylic Syrups Prepared via a Free Radical Photopolymerization Process. Polymers 2021, 13, 189. [CrossRef]

31. Benedek, I. Pressure-Sensitive Adhesives and Applications; Marcel Deker Inc.: New York, NY, USA, 2004; pp. 92-102. 